\title{
Efficient Catalytic System Involving Molybdenyl Acetylacetonate and Immobilized Tributylammonium Chloride for the Direct Synthesis of Cyclic Carbonates from Carbon Dioxide and Olefins
}

\author{
Agnieszka Siewniak $^{1} \cdot$ Katarzyna Jasiak-Jaroń $^{1} \cdot$ Lukasz Kotyrba $^{1} \cdot$ Stefan Baj $^{1}$
}

Received: 1 January 2017 / Accepted: 4 March 2017 / Published online: 29 March 2017

(C) The Author(s) 2017. This article is an open access publication

\begin{abstract}
An effective direct method for preparing of cyclic carbonates from $\mathrm{CO}_{2}$ and olefins in the presence of tert-butyl hydroperoxide as an oxidant was provided. The first stage, the epoxidation of olefins, was carried out using $\mathrm{MoO}_{2}(\mathrm{acac})_{2}$ as a catalyst $\left(1 \mathrm{~h}, 100^{\circ} \mathrm{C}\right)$, and the second stage, the cycloaddition of $\mathrm{CO}_{2}$ to the resulting epoxide, was proceeded in the presence of immobilized tributylmethylammonium chloride on a polystyrene cross-linked with divinylbenzene, and an aqueous solution of $\mathrm{ZnBr}_{2}$ $\left(100^{\circ} \mathrm{C}, 0.9 \mathrm{MPa}\right.$ of $\left.\mathrm{CO}_{2}, 4 \mathrm{~h}\right)$. The proposed method allowed to obtain cyclic carbonates with high yields $(50$ 77\%) under mild conditions. Moreover, the immobilized catalyst could be reused at least five times without significant loss of its catalytic activity.
\end{abstract}

\section{Graphical Abstract}

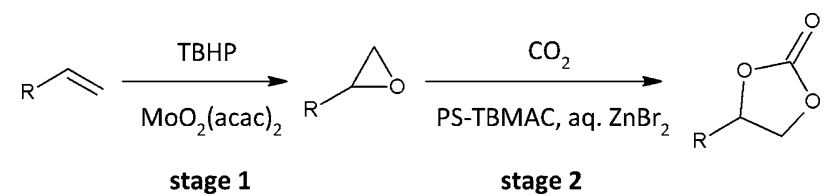

Keywords Carbon dioxide - Cyclic carbonates . Immobilization $\cdot$ Epoxidation $\cdot$ Cycloaddition

Electronic supplementary material The online version of this article (doi:10.1007/s10562-017-2020-x) contains supplementary material, which is available to authorized users.

Agnieszka Siewniak

agnieszka.siewniak@polsl.pl

1 Department of Chemical Organic Technology and Petrochemistry, Faculty of Chemistry, Silesian University of Technology, Krzywoustego 4, 44-100 Gliwice, Poland

\section{Introduction}

Inexpensive, readily available carbon dioxide plays an important role as a renewable raw material in several industrial processes. Among them, the synthesis of cyclic carbonates is of particular interest. The demand for cyclic carbonates continues to grow due to the wide range of their applications. They are used for polymer production e.g. non-isocyanate polyurethanes, polycarbonates; and as important intermediates in many processes for the preparation of fine chemicals. They are also employed as solvents, and components of electrolytes for lithium-ion batteries [1-4].

An important industrial method for preparing cyclic carbonate is by reaction of $\mathrm{CO}_{2}$ with epoxides [5]. However, it is possible to carry out their synthesis from olefins and $\mathrm{CO}_{2}$. This method involves two stages: the epoxidation of olefins and the cycloaddition of $\mathrm{CO}_{2}$ to the resulting epoxide. Due to the fact there is no need to isolate the epoxide, and the olefins are cheaper feedstock than epoxides, this method can be advantageous from an economic and environmental point of view. Although, the first report on this reaction appeared in 1962 [6], it has not yet been implemented on an industrial scale.

The direct synthesis of cyclic carbonates from carbon dioxide and olefins is typically conducted at temperature $30-150^{\circ} \mathrm{C}$ and under pressure of $\mathrm{CO}_{2}$ in the range of 1-15 MPa. Among others, metals, metal oxides, metal complexes, quaternary onium salts, and ionic liquids, are used as catalysts. Oxygen, hydrogen peroxide, alkyl hydroperoxides and urea hydroperoxide are usually used as oxidizing agents in the epoxidation stage $[7,8]$.

The synthesis of cyclic carbonates using alkyl hydroperoxides as oxidands is carried out mainly in the presence of metals, ionic liquids, and quaternary onium salts as 
catalysts. Conducting the reaction using tert-butyl hydroperoxide (TBHP) as an oxidant and titanosilicate molecular sieves (TiMCM-41) and $N, N$-dimethylaminopyridine as a catalyst system in acetonitrile as a solvent, allowed to achieve conversion of olefin to epoxide only in the range of $13-44 \%$, and $97-100 \%$ conversion of the resulting epoxide to cyclic carbonate with selectivities in the range $83-100 \%$ [9]. Arai et al. reported the synthesis of styrene carbonate (SC) from styrene (ST), TBHP and $\mathrm{CO}_{2}$ using ionic liquids based on 1-n-alkyl-3-methylimidazolium or tetrabutylammonium cation as catalysts $[10,11]$. The most effective catalyst was tetrabutylammonium bromide (TBAB), however, SC was obtained only in $38 \%$ yield (reaction conditions: $80^{\circ} \mathrm{C}, \mathrm{a} \mathrm{CO}_{2}$ pressure of $1 \mathrm{MPa}$ ). In 2005 , the same group developed a method for preparation styrene carbonate, in which a silica-supported gold catalyst was used for the epoxidation of styrene with cumene hydroperoxide (CHP) or TBHP, while $\mathrm{ZnBr}_{2}$ and TBAB were applied for the second stage of the process [12]. The reaction was carried out at the temperature of $80^{\circ} \mathrm{C}$ and under the pressure of $1 \mathrm{MPa}$. The highest yield that has been achieved for styrene carbonate was $45 \%$. Sun and co-workers proposed the catalyst system consisting of $\mathrm{Au}$ supported on $\mathrm{Fe}(\mathrm{OH})_{3}$, $\mathrm{ZnBr}_{2}$ and $\mathrm{TBAB}$ for the synthesis of styrene carbonate using $\mathrm{CHP}$ as an oxidant [13]. Under reaction conditions of $80^{\circ} \mathrm{C}, \mathrm{CO}_{2}$ pressure of $4 \mathrm{MPa}$, styrene carbonate was obtained in yield of $53 \%$ after $10 \mathrm{~h}$. In turn, the use of gold (0.01 wt\%) supported on R201 resin functionalized with quaternary ammonium functional groups allowed to obtain styrene carbonate in $51 \%$ yield [14]. The reaction selectivity was $52 \%$. Styrene carbonate can also be obtained in the reaction conducted in the presence of the $\mathrm{MoO}_{2}(\mathrm{acac})_{2}$, TBAB catalytic system and TBHP as an oxidant [15]. The styrene epoxidation reaction was carried out for $1 \mathrm{~h}$ at the temperature of $100^{\circ} \mathrm{C}$. Next, the reaction of the resulting styrene oxide with carbon dioxide was conducted for $1 \mathrm{~h}\left(140^{\circ} \mathrm{C}, \mathrm{CO}_{2}\right.$ pressure of $\left.3 \mathrm{MPa}\right)$. $\mathrm{SC}$ was obtained in $68 \%$ yield whereas yields of other cyclic carbonates was in the range from 45 to $84 \% .44 \%$ selectivity to $\mathrm{SC}$ at $57 \%$ styrene conversion was achieved in the reaction conducted with chromium-organic frameworks and TBAB as a catalyst system, at temperatures of $25-100^{\circ} \mathrm{C}$ and a $\mathrm{CO}_{2}$ pressure of 8-100 bar [16]. The ionic liquid 1-butyl3-methylimidazolium bromide was used in a one-pot reaction $\left(150^{\circ} \mathrm{C}, 0.5 \mathrm{MPa}\right.$ of $\left.\mathrm{CO}_{2}, 6 \mathrm{~h}\right)$ allowed to obtain $\mathrm{SC}$ with $40 \%$ selectivity at $90 \%$ conversion of styrene, whereas SC was obtained with a selectivity of $63 \%$ at $99 \%$ conversion of styrene in the reaction conducted in a single reactor under different conditions for each step (epoxidation step: $100^{\circ} \mathrm{C}, 16 \mathrm{~h}$, cycloaddition step: $150^{\circ} \mathrm{C}, 0.5 \mathrm{MPa}$, 6 h) [17]. Recently, polyoxometalate-based homochiral metal-organic frameworks were used as catalysts for enantioselective synthesis of cyclic carbonates in the presence of TBHP as an oxidant [18]. Use of mild reaction conditions $\left(50^{\circ} \mathrm{C}, 0.5 \mathrm{MPa}\right)$ but long reaction times $(96 \mathrm{~h})$ allowed for the preparation of cyclic carbonates with yields in the range $72-92 \%$ and the enantioselectivity of $55-80 \%$. The catalyst could be used three times without a significant reduction in its activity. Gosh et al. used the catalyst system consisting of a manganese(III) complex of an amidoamine ligand and TBAB for direct synthesis of cyclic carbonates [19]. The yields in the range of $10-48 \%$ were obtained under the reaction conditions: $100^{\circ} \mathrm{C}, 250 \mathrm{psig}$ of $\mathrm{CO}_{2}$, using acetonitrile as a solvent. Cyclic carbonates can be obtained with a selectivity of $44-68 \%$ at a conversion of olefin in the range of $62-98.5 \%$ using mesoporous titanium-silicate catalyst and TBAB as a cocatalyst [20]. The reaction conditions were relatively mild: $50-70^{\circ} \mathrm{C}, \mathrm{a} \mathrm{CO}_{2}$ pressure of $0.8 \mathrm{MPa}$, but the reaction time was $48 \mathrm{~h}$.

The problems in above methods are usually not only unsatisfying yields of cyclic carbonates and low selectivities, but also long reaction time, often not easy synthesis of catalysts and their high price as well as difficulties associated with separation of the catalyst system and the inability to its reuse. It should also be emphasized that most of the described methods concerns only the synthesis of styrene carbonate.

Herein, we report an efficient one-pot procedure for the synthesis of cyclic carbonates directly from $\mathrm{CO}_{2}$ and olefins using tert-butyl hydroperoxide as an oxidant. According to our previous studies, the reaction of $\mathrm{CO}_{2}$ with epoxides could be carried out with high selectivities and yields in the presence of the catalyst system consisting of an immobilized quaternary ammonium salt on a polymeric carrier and an aqueous solution of zinc bromide(II) [21]. Therefore, this catalyst system was used for the second stage of the reaction of $\mathrm{CO}_{2}$ with olefins, while molybdenyl acetylacetonate $\left(\mathrm{MoO}_{2}(\mathrm{acac})_{2}\right)$ was used as a catalyst for epoxidation of olefins.

\section{Experimental}

\subsection{Chemical and Materials}

Carbon dioxide (99.5\%, from SIAD) was used without further purification. Bis(acetylacetonato) dioxomolybdenum(VI) (molybdenyl acetylacetonate, $\mathrm{MoO}_{2}(\mathrm{acac})_{2}$ ), styrene (99\%), styrene oxide (>97\%), tributylamine (99\%) were provided by Acros Organic. (Chloromethyl)ethylene carbonate, cyclohexene (99\%), cyclohexene oxide (98\%), 1-octene (98\%), octane (>99\%), $5.5 \mathrm{M}$ solution of tert-butyl hydroperoxide (TBHP) in decane, were purchased from Sigma Aldrich. Epichlorohydrin (>99\%), tributylmethylammonium chloride (TBMAC) and tributylmethylammonium chloride polymer bound 
(PS-TBMAC, 200-400 mesh; Cl loading: $1.2 \mathrm{mmol} / \mathrm{g}$, polystyrene $1 \%$ cross-linked with DVB) were obtained from Fluka. Zinc bromide(II) (>98\%) was bought from POCH S.A.

\subsection{Instrumentation}

The pressure reactions were carried out in $100 \mathrm{ml}$ autoclave (EM-60-100-SS-HC) placed in a solid-state thermostat (EasyMax ${ }^{\mathrm{TM}}$ 102, Mettler Toledo). The pressure reactor was equipped with a mechanical stirrer (pitched-blade), temperature and pressure sensors and a rapture disc. Samples were analyzed by gas chromatography using PerkinElmer Clarus 500 chromatograph equipped with a flame ionization detector (FID) and a capillary column (SPB$5^{\mathrm{TM}}: 30 \mathrm{~m} \times 0.25 \mathrm{~mm} \times 0.25 \mu \mathrm{m}$ film thickness). GC-MS analyses were performed on a gas chromatography-mass spectrometry system (Agilent Technologies 7890 A GC system, Agilent Technologies $5975 \mathrm{C}$ inert XL EI/CI MS System) equipped with a capillary column (HP5/MS-5: $30 \mathrm{~m} \times 0.25 \mathrm{~mm} \times 0.25 \mu \mathrm{m}$ film thickness). Octane or nonane were used as the internal standards for the quantification of the formation of the products. The conditions of MS analysis were as follows: EI, ionization voltage $70 \mathrm{eV}$, ion source temperature $230^{\circ} \mathrm{C}, \mathrm{m} / \mathrm{z}$ range 33-550. NMR spectra were recorded using a Varian 600 or $400 \mathrm{MHz}$ for ${ }^{1} \mathrm{H}$ NMR and 150 or $100.6 \mathrm{MHz}{ }^{13} \mathrm{C}$ NMR. Elementary analyses were performed on a PerkinElmer 2400 series $2 \mathrm{CHNO} / \mathrm{S}$ analyzer. Infrared spectroscopy (IR) was conducted on a FT-IR spectrometer Mettler-Toledo IC10 with ATR probe. The parameters of the FT-IR spectrometer: measuring range: $4000-650 \mathrm{~cm}^{-1}$, resolution: 4 , 8 or $16 \mathrm{~cm}^{-1}$, operating temperature range: from -80 to $+200^{\circ} \mathrm{C}$.

\subsection{General Procedure of Cyclic Carbonates Synthesis}

\section{Procedure 1 An olefin $(58 \mathrm{mmol}), \quad \mathrm{MoO}_{2}(\mathrm{acac})_{2}$} (0.058 mmol), TBHP (64 mmol), PS-TBMAC $(0.58 \mathrm{mmol})$, an aqueous solution of $\mathrm{ZnBr}_{2}(0.80 \mathrm{mmol}$ of $\mathrm{H}_{2} \mathrm{O}, 0.16 \mathrm{mmol}$ of $\mathrm{ZnBr}_{2}$ ), and an internal standard ( $0.4 \mathrm{~g}$ octane, or nonane, depending on the olefin used in the process) were added into an autoclave. The reactor was sealed and purged two times with carbon dioxide. Then, the reaction mixture was stirred $(500 \mathrm{rpm})$ and heated up to $100^{\circ} \mathrm{C}$. After stabilization of the temperature, the autoclave was filled with carbon dioxide to the appropriate pressure (0.5-2.0 MPa). Process was conducted for $5 \mathrm{~h}$. Procedure 2: An olefin (58 mmol), $\mathrm{MoO}_{2}(\mathrm{acac})_{2}(0.058 \mathrm{mmol}), \mathrm{TBHP}$ (64 mmol), PS-TBMAC $(0.58 \mathrm{mmol})$ and an aqueous solution of $\mathrm{ZnBr}_{2}\left(0.80 \mathrm{mmol}\right.$ of $\mathrm{H}_{2} \mathrm{O}, 0.16 \mathrm{mmol}$ of $\left.\mathrm{ZnBr}_{2}\right)$, an internal standard ( $0.4 \mathrm{~g}$ octane, or nonane, depending on the olefin used in the process) were added into an autoclave.
The reactor was sealed and the reaction mixture was stirred $(500 \mathrm{rpm})$ and heated up to $100^{\circ} \mathrm{C}$. After $1 \mathrm{~h}$, the autoclave was filled with carbon dioxide to the appropriate pressure $(0.9 \mathrm{MPa})$ and reaction was conducted for $4 \mathrm{~h}$. Procedure 3: An olefin (58 mmol), $\mathrm{MoO}_{2}(\mathrm{acac})_{2}(0.058 \mathrm{mmol}), \mathrm{TBHP}$ (64 mmol), an internal standard (0.4 g octane, or nonane, depending on the olefin used in the process) were added into an autoclave. The reactor was sealed and the reaction mixture was stirred $(500 \mathrm{rpm})$ at $100^{\circ} \mathrm{C}$ for $1 \mathrm{~h}$. After completion of the first stage of the process, the reactor content was cooled to room temperature. Then, the catalyst system required to carry out the second stage of the process, consisting of PS-TBMAC $(0.58 \mathrm{mmol})$ and an aqueous solution of $\mathrm{ZnBr}_{2}\left(0.80 \mathrm{mmol}\right.$ of $\mathrm{H}_{2} \mathrm{O}, 0.16 \mathrm{mmol}$ of $\left.\mathrm{ZnBr}_{2}\right)$, was added. The reaction mixture was again heated up to the desired temperature $\left(90-130^{\circ} \mathrm{C}\right)$. After stabilization of the temperature, the autoclave was filled with carbon dioxide to the appropriate pressure (0.5-2.0 MPa) and reaction was conducted for $4 \mathrm{~h}$. Product isolation: After the completion of the reaction, the mixture was cooled to room temperature and filtered to remove PS-TBMAC. The filtrate was concentrated and then extracted with ethanol $(3 \times 5 \mathrm{ml})$ in order to remove $\mathrm{MoO}_{2}(\mathrm{acac})_{2}$ which precipitated out as a solid. The organic phase was dried over anhydrous $\mathrm{MgSO}_{4}$ and concentrated under reduced pressure. The crude product was purified by column chromatography (hexane/chloroform). GC Analysis: On completion the reaction was cooled to room temperature and the excess carbon dioxide was vented. Then, the reaction mixture was diluted with $5 \mathrm{ml}$ of ethyl acetate and sample of the reaction mixture $(5 \mu \mathrm{l})$ was taken, dissolved in ethyl acetate $(900 \mu \mathrm{l})$, and analyzed by gas chromatography. Catalyst reusability: After the completion of the reaction, the immobilized catalyst was simply recovered by filtration, washed with dichloromethane $(6 \times 5 \mathrm{ml})$. The filtrate was extracted with ethanol $(3 \times 5 \mathrm{ml})$ in order to extract $\mathrm{MoO}_{2}(\mathrm{acac})_{2}$. The separated PS-TBMAC during the filtration was dried in vacuum and then reused for the next run.

\section{Results and Discussion}

The research was conducted on the example of a model reaction between styrene and carbon dioxide (Fig. 1). The first stage of the process, the epoxidation of styrene with $5.5 \mathrm{M}$ solution of tert-butyl hydroperoxide in decane, was conducted in the presence of $\mathrm{MoO}_{2}(\mathrm{acac})_{2}$ as a catalyst. Based on our previous results [21], for the second step, the cycloaddition of $\mathrm{CO}_{2}$ to styrene oxide (SO), the catalyst system consisting of an immobilized tributylmethylammonium chloride on a polystyrene cross-linked with divinylbenzene (PS-TBMAC) and an aqueous solution of 
Fig. 1 Model reaction between styrene and carbon dioxide

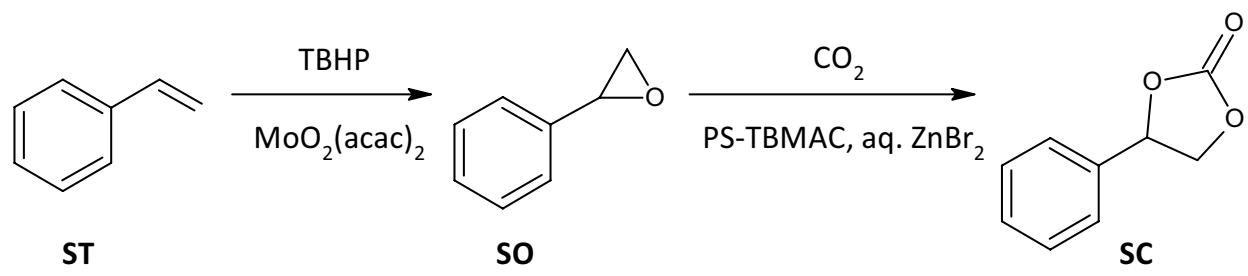

Table 1 The choice of procedure for conducting the direct synthesis of styrene carbonate form $\mathrm{CO}_{2}$ and styrene

\begin{tabular}{lllrrr}
\hline Entry & Procedure & $\begin{array}{l}\text { Conversion of the } \\
\text { styrene }(\%)\end{array}$ & \multicolumn{3}{l}{ Yield $^{\mathrm{a}}(\%)$} \\
\cline { 4 - 6 } & & & SO & BA & SC \\
\hline $1^{\mathrm{b}}$ & 1 & 79 & 8 & 17 & 22 \\
$2^{\mathrm{b}}$ & 2 & 82 & 11 & 19 & 43 \\
$3^{\mathrm{b}}$ & 3 & 96 & 8 & 11 & 67 \\
$4^{\mathrm{c}}$ & 3 & 94 & 21 & 6 & 42 \\
$5^{\mathrm{d}}$ & 3 & 92 & 6 & 23 & 51 \\
$6^{\mathrm{e}}$ & 3 & 94 & 8 & 25 & 57 \\
\hline
\end{tabular}

Reaction conditions: styrene $(58 \mathrm{mmol}), 5.5 \mathrm{M}$ solution of TBHP in decane $(64 \mathrm{mmol}), \mathrm{MoO}_{2}(\mathrm{acac})_{2}(0.058 \mathrm{mmol})$, a quaternary ammonium salt $(0.58 \mathrm{mmol})$, an aqueous solution of $\mathrm{ZnBr}_{2}(0.80 \mathrm{mmol}$ of $\mathrm{H}_{2} \mathrm{O}, 0.16 \mathrm{mmol}$ of $\left.\mathrm{ZnBr}_{2}\right), 500 \mathrm{rpm}$. ${ }^{\mathrm{a}}$ Determined by GC. ${ }^{\mathrm{b}} \mathrm{PS}$ TBMAC. ${ }^{\mathrm{C}} \mathrm{TBMAC}{ }^{\mathrm{d}} \mathrm{TBAB}$ without aqueous solution of $\mathrm{ZnBr}_{2}$. ${ }^{\mathrm{e}} \mathrm{TBAB}$. Procedure 1: all reagents including the catalyst system consisting of $\mathrm{MoO}_{2}(\mathrm{acac})_{2}$, PS-TBMAC, aq. $\mathrm{ZnBr}_{2}$, were added simultaneously to the reactor. Process was conducted at $100^{\circ} \mathrm{C}$, under a $\mathrm{CO}_{2}$ pressure of $0.9 \mathrm{MPa}$ for $5 \mathrm{~h}$. Procedure 2: the first stage of process was conducted in the presence of the catalyst system consisting of $\mathrm{MoO}_{2}(\mathrm{acac})_{2}$, PS-TBMAC, aq. $\mathrm{ZnBr}_{2}$, at $100^{\circ} \mathrm{C}$ for $1 \mathrm{~h}$, after this time carbon dioxide $\left(\mathrm{CO}_{2}\right.$ pressure of $\left.0.9 \mathrm{MPa}\right)$ was added to the reactor and the second step was conducted at $100^{\circ} \mathrm{C}$ for $4 \mathrm{~h}$. Procedure 3: the first stage of process was conducted in the presence of $\mathrm{MoO}_{2}(\mathrm{acac})_{2}$ as catalyst at $100^{\circ} \mathrm{C}$ for $1 \mathrm{~h}$, after this time carbon dioxide (a $\mathrm{CO}_{2}$ pressure of $\left.0.9 \mathrm{MPa}\right)$ and the catalyst system consisting of PS-TBMAC (or TBMAC, TBAB) with or without an aqueous solution of $\mathrm{ZnBr}_{2}$ were added to the reactor and the second step was conducted for $4 \mathrm{~h}$

zinc bromide(II) (molar ratio of $\mathrm{H}_{2} \mathrm{O}$ to $\mathrm{ZnBr}_{2}$ 5: 1), was applied.

\subsection{The Impact of the Order of Reagent Introduction}

The order in which reagents are added to a reactor can be crucial for the reaction of $\mathrm{CO}_{2}$ with olefins. The introduction of all reagents: $\mathrm{CO}_{2}$, styrene, TBHP with the catalyst system consisting of $\mathrm{MoO}_{2}(\mathrm{acac})_{2}$, PS-TBMAC and an aqueous solution of $\mathrm{ZnBr}_{2}$, allowed to obtain styrene carbonate with only $22 \%$ yield (Table 1 , entry 1 ). The unreacted styrene oxide (8\%) and benzaldehyde (BA) (17\%) were also present in the reaction mixture. In this case, both stages of the process were carried out under the same conditions of temperature and pressure (procedure $1: 100^{\circ} \mathrm{C}$, the initial $\mathrm{CO}_{2}$ pressure of $0.9 \mathrm{MPa}, 500 \mathrm{rpm}, 5 \mathrm{~h}$ ). Sun et al. also observed that the presence of $\mathrm{CO}_{2}$ has a negative effect on the epoxidation reaction [14]. In contrast, Arai et al. found that the addition of carbon dioxide to the first reaction step results in improved yield both SO and SC [11]. A low yield of styrene carbonate was obtained possibly due to the fact that the epoxidation of styrene in the presence of $\mathrm{CO}_{2}$ could allow the formation of the linear oligomers and polycarbonates, which in turn could impede the subsequent reaction of carbon dioxide with in situ formed epoxide $[22,23]$. Therefore, in the next experiment, $\mathrm{CO}_{2}$ was added to the reactor in the second step of the process. The first step proceeded at the temperature of $100^{\circ} \mathrm{C}$. Only after one hour carbon dioxide was added $(0.9 \mathrm{MPa})$ and the reaction was carried out for additional $4 \mathrm{~h}$ (procedure 2). This resulted in about a two-fold increase in cyclic carbonate yield (43\%) (Table 1, entry 2).

The quaternary ammonium salt with a halogen anion could catalyze the decomposition reaction of tert-butyl hydroperoxide and $\mathrm{MoO}_{2}(\mathrm{acac})_{2}$, resulting in the formation of oxygen, tert-butanol and $\mathrm{MoO}_{2} \mathrm{Br}_{2}$ [15]. Thus, in a further experiment $\mathrm{CO}_{2}$, PS-TBMAC and an aqueous solution of $\mathrm{ZnBr}_{2}$ were added to the reaction system after one hour (procedure 3). The yield of cyclic carbonate was $67 \%$ (Table 1, entry 3 ).

In order to compare, a course of reaction in the presence of tributylmethylammonium chloride (TBMAC), which is a soluble counterpart of PS-TBMAC, the process was carried out according to the procedure 3 . As can be seen from Table 1 (entry 4), the PS-TBMAC showed higher catalytic activity than its homogeneous counterpart. On the one hand, this might be due to the increased lipophilicity of quaternary ammonium salt immobilized onto the polymer carrier and thus easier contact of the reactants with active sites of the catalyst. On the other hand, the immobilized catalyst could show higher stability under reaction conditions. Based on the GC-MS analysis, it was found that during the process, $20 \%$ of TBMAC underwent decomposition to tributylamine, which could have a significant impact on reducing its activity. Moreover, a large amount of unreacted styrene oxide (an intermediate product) in the post-reaction mixture also confirmed the lower tributylmethylammonium chloride activity in the second stage of the process. By contrast, in the case of using PS-TBMAC, tributylamine was observed in an amount less than $1 \%$.

Under the same conditions (procedure 3 ) the reaction in presence of TBAB as a catalyst of the second stage of the 
Table 2 The influence of temperature and $\mathrm{CO}_{2}$ pressure on the second stage of the direct synthesis of styrene carbonate from $\mathrm{CO}_{2}$ and styrene

\begin{tabular}{|c|c|c|c|c|c|c|c|}
\hline \multirow[t]{2}{*}{ Entry } & \multirow{2}{*}{$\begin{array}{l}\text { Temperature of the } \\
2 \text { stage }\left({ }^{\circ} \mathrm{C}\right)\end{array}$} & \multirow{2}{*}{$\begin{array}{l}\mathrm{CO}_{2} \text { pressure } \\
(\mathrm{MPa})\end{array}$} & \multirow{2}{*}{$\begin{array}{l}\text { Amount of the PS- } \\
\text { TBMAC }(\% \mathrm{~mol})\end{array}$} & \multirow{2}{*}{$\begin{array}{l}\text { Conversion of } \\
\text { ST }(\%)\end{array}$} & \multicolumn{3}{|c|}{ Yield $^{\mathrm{a}}(\%)$} \\
\hline & & & & & $\mathrm{SO}$ & BA & $\mathrm{SC}$ \\
\hline 1 & 90 & 0.9 & 1.0 & 96 & 32 & 6 & 31 \\
\hline 2 & 100 & 0.9 & 1.0 & 96 & 8 & 11 & 67 \\
\hline 3 & 110 & 0.9 & 1.0 & 97 & 5 & 7 & 45 \\
\hline 4 & 120 & 0.9 & 1.0 & 96 & 9 & 5 & 30 \\
\hline 5 & 130 & 0.9 & 1.0 & 98 & 2 & 8 & 19 \\
\hline 6 & 100 & 0.5 & 1.0 & 96 & 21 & 6 & 29 \\
\hline 7 & 100 & 1.5 & 1.0 & 97 & 4 & 4 & 51 \\
\hline 8 & 100 & 2.0 & 1.0 & 97 & 4 & 4 & 34 \\
\hline 9 & 100 & 0.9 & 1.5 & 97 & 8 & 10 & 68 \\
\hline 10 & 100 & 0.9 & 3.0 & 97 & 13 & 8 & 70 \\
\hline
\end{tabular}

Reaction conditions: styrene $(58 \mathrm{mmol}), 5.5 \mathrm{M}$ solution of TBHP in decane $(64 \mathrm{mmol}), \mathrm{MoO}_{2}(\mathrm{acac})_{2}$ $(0.058 \mathrm{mmol})$, PS-TBMAC, aqueous solution of $\mathrm{ZnBr}_{2}\left(0.80 \mathrm{mmol}\right.$ of $\mathrm{H}_{2} \mathrm{O}, 0.16 \mathrm{mmol}$ of $\left.\mathrm{ZnBr}_{2}\right)$, $500 \mathrm{rpm}$. The first step of process was conducted in the presence of $\mathrm{MoO}_{2}(\mathrm{acac})_{2}$ at $100^{\circ} \mathrm{C}, 1 \mathrm{~h}$; after this time carbon dioxide $\left(\mathrm{a} \mathrm{CO}_{2}\right.$ pressure of $\left.0.9 \mathrm{MPa}\right)$ and the catalyst system consisting of PS-TBMAC and aq. $\mathrm{ZnBr}_{2}$ were added to the reactor and the second step was conducted for $4 \mathrm{~h}$. ${ }^{\mathrm{a}}$ Determined by GC process (Table 1, entry 5), and the reaction with the catalyst system consisting of TBAB and aq. $\mathrm{ZnBr}_{2}$, were carried out (Table 1, entry 6). In both cases, the yield of SC was lower than that obtained in the case of using PS-TBMAC and aq. $\mathrm{ZnBr}_{2}$.

\subsection{The Choice of Conditions of the Second Step of the Process}

Conditions for carrying out the first reaction step using $\mathrm{MoO}_{2}(\mathrm{acac})_{2}$ as a catalyst, have been chosen on the basis of literature data $\left(100^{\circ} \mathrm{C}, 1 \mathrm{~h}\right)$ [15]. Whereas, the influence of temperature and $\mathrm{CO}_{2}$ pressure on the course of the second stage of the reaction was examined. Optimal conditions for conducting the second stage of the direct synthesis of cyclic carbonates may be different from those we have specified for their synthesis from epoxides and $\mathrm{CO}_{2}$ in the presence of PS-TBMAC [21], since in this case the reaction mixture is more complex. As shown in Table 2, the temperature increase from 90 to $100^{\circ} \mathrm{C}$ in the second stage of the process caused more than two-fold increase in a yield of styrene carbonate. When the temperature raised, the rate of the reaction of carbon dioxide with in situ formed styrene oxide also increased. However, a further increase of temperature above $100^{\circ} \mathrm{C}$ had an unfavorable effect on the reaction course.

The styrene carbonate yield increased with pressure increasing from 0.5 to $0.9 \mathrm{MPa}$. However, a further increase in the $\mathrm{CO}_{2}$ pressure resulting in lowered SC yield. This phenomenon has also been observed by other researchers. Some of them explain that too high concentration of carbon dioxide in the reaction mixture can hinder the interaction between styrene and catalyst [13].
Moreover, at high pressure of $\mathrm{CO}_{2}$, the formation of oligomers can be promoted [14].

The increase of the amount of immobilized catalyst in the studied range (1-3 mol\% to styrene) has a negligible impact on the yield of styrene carbonate. It should also be emphasized that the excessive amount of the immobilized catalyst in the reaction system may impede mixing of the reaction mixture.

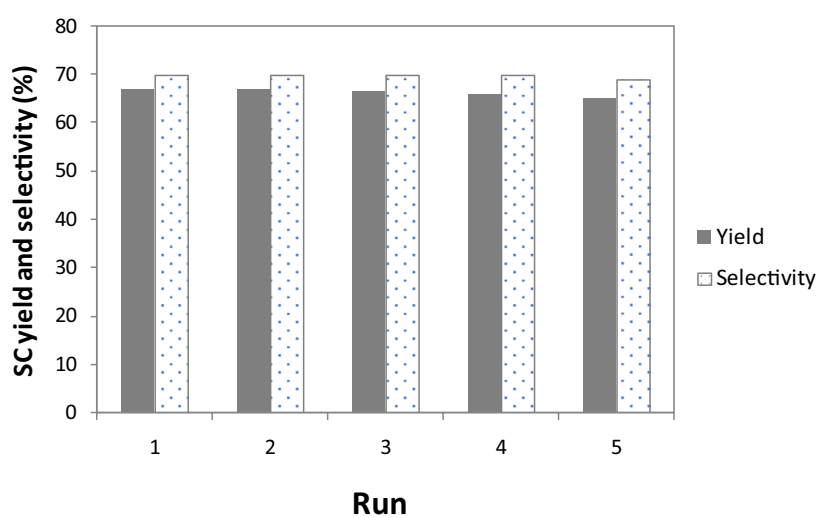

Fig. 2 PC yield and selectivity in the reaction of $\mathrm{CO}_{2}$ with styrene in the presence of recycled PS-TBMAC catalyst. Reaction conditions: styrene $(58 \mathrm{mmol}), 5.5 \mathrm{M}$ solution of TBHP in decane (64 mmol), $\mathrm{MoO}_{2}(\mathrm{acac})_{2}(0.058 \mathrm{mmol})$, PS-TBMAC $(0.58 \mathrm{mmol})$, aqueous solution of $\mathrm{ZnBr}_{2}\left(0.80 \mathrm{mmol}\right.$ of $\mathrm{H}_{2} \mathrm{O}, 0.16 \mathrm{mmol}$ of $\left.\mathrm{ZnBr}_{2}\right)$, $500 \mathrm{rpm}$. The first step of process was conducted in the presence of $\mathrm{MoO}_{2}(\mathrm{acac})_{2}$ at $100^{\circ} \mathrm{C}, 1 \mathrm{~h}$, after this time carbon dioxide (a $\mathrm{CO}_{2}$ pressure of $0.9 \mathrm{MPa}$ ) and the catalyst system consisting of PSTBMAC and aq. $\mathrm{ZnBr}_{2}$ were added to the reactor and the second step was conducted for $4 \mathrm{~h}$ 
Table 3 Synthesis of various cyclic carbonates from olefins and $\mathrm{CO}_{2}$

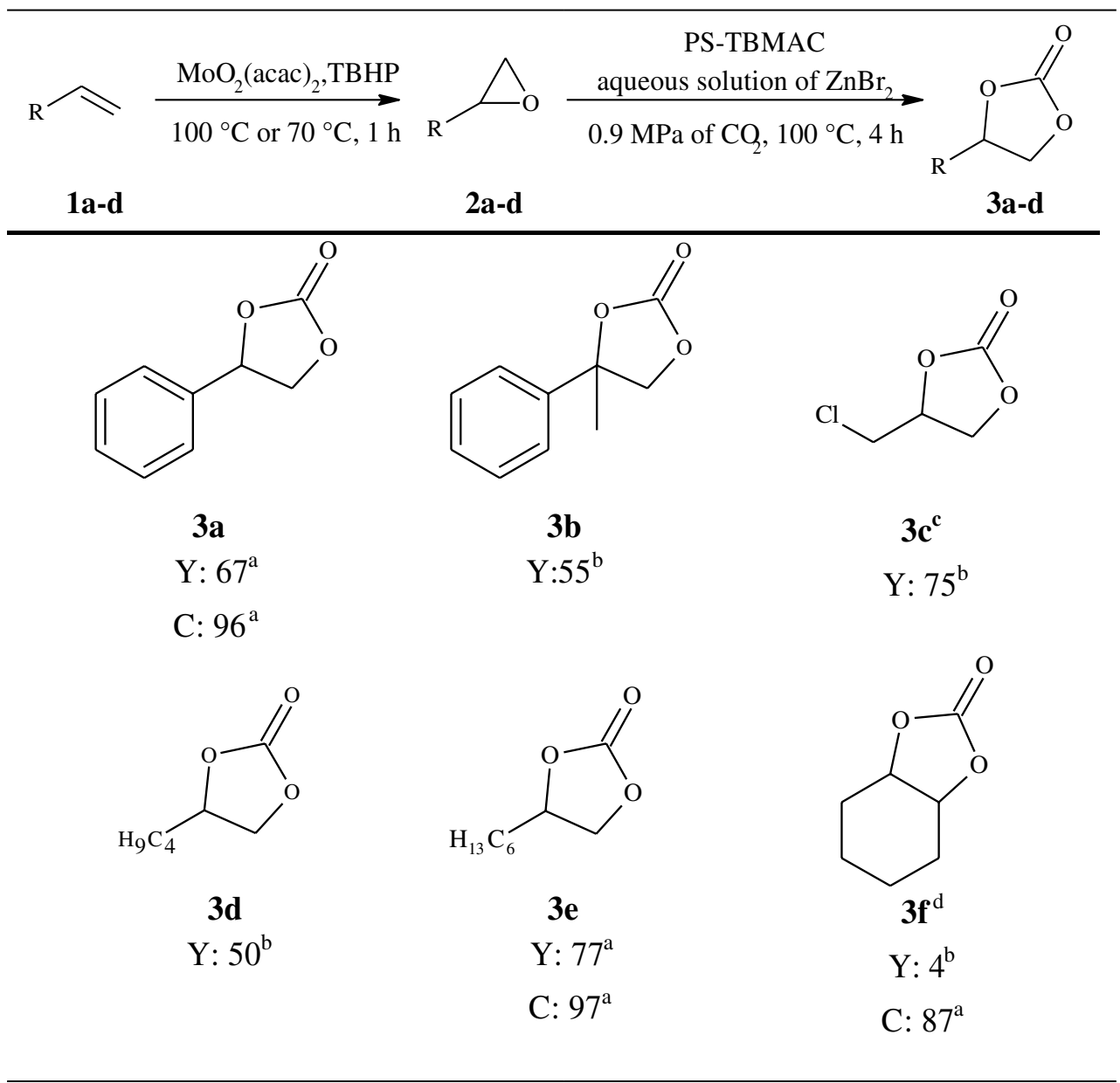

Reaction conditions: olefin $(58 \mathrm{mmol}), 5.5 \mathrm{M}$ solution of TBHP in decane $(64 \mathrm{mmol}), \mathrm{MoO}_{2}(\mathrm{acac})_{2}$ $(0.058 \mathrm{mmol})$, PS-TBMAC $(0.58 \mathrm{mmol})$, aqueous solution of $\mathrm{ZnBr}_{2}\left(0.80 \mathrm{mmol}\right.$ of $\mathrm{H}_{2} \mathrm{O}, 0.16 \mathrm{mmol}$ of $\left.\mathrm{ZnBr}_{2}\right), 500 \mathrm{rpm}$. The first step of the process was conducted in the presence of $\mathrm{MoO}_{2}(\mathrm{acac})_{2}$ at $100^{\circ} \mathrm{C}$, $1 \mathrm{~h}$; after this time carbon dioxide $\left(\mathrm{CO}_{2}\right.$ pressure of $\left.0.9 \mathrm{MPa}\right)$ and the catalyst system consisting of PSTBMAC and aq. $\mathrm{ZnBr}_{2}$ were added to the reactor and the second step was conducted for $4 \mathrm{~h}$. $\mathrm{Y}$-yield of cyclic carbonate (\%), C-olefin conversion (\%). ${ }^{\mathrm{a}}$ Determined by GC. ${ }^{\mathrm{b}}$ Determined by ${ }^{1} \mathrm{H}$ NMR. ${ }^{\mathrm{c}}$ Temperature of the first stage: $70^{\circ} \mathrm{C}$. ${ }^{\mathrm{d}} \mathrm{Cis}$-isomer, time of the second stage: $10 \mathrm{~h}$

\subsection{Studies on the Recycle of PS-TBMAC}

Reusability of the catalyst is important from the economic point of view. Therefore, study on the recovery and reuse of the catalyst system was conducted. The process was performed under the optimized conditions described above (the first step at $100^{\circ} \mathrm{C}$ for $1 \mathrm{~h}$, the second step at $100^{\circ} \mathrm{C}$ and under a pressure of $0.9 \mathrm{MPa} \mathrm{CO}_{2}$ for $4 \mathrm{~h}$ ).

The immobilized PS-TBMAC catalyst was separated from the reaction mixture by filtration, whereas molybdenyl acetylacetonate by extraction with ethanol and subsequent filtration of the precipitated catalyst. These catalysts with a fresh solution of zinc bromide were used for the next process for the preparation of styrene carbonate. However, the yield of styrene carbonate was lower than for the fresh catalyst system. This may be due to losses in the recovery of $\mathrm{MoO}_{2}(\mathrm{acac})_{2}$, because it was used in very small amount in the process. The recovery of $\mathrm{MoO}_{2}(\mathrm{acac})_{2}$ was only $48 \%$. Therefore, in subsequent reactions, the addition of fresh $\mathrm{MoO}_{2}(\mathrm{acac})_{2}$ was used. It should be noted that if the reaction is conducted on a large scale, these losses may be negligible.

The results shown in Fig. 2, indicate that the PSTBMAC catalyst exhibited high activity in five successive cycles of reaction. Cyclic carbonate yields in subsequent cycles ranged $65-67 \%$.

\subsection{Synthesis of Cyclic Carbonates from Selected Olefins and $\mathrm{CO}_{2}$}

The cyclic carbonates from selected olefins and $\mathrm{CO}_{2}$ in the presence of the developed catalytic system: $\mathrm{MoO}_{2}(\mathrm{acac})_{2} /$ PS-TBMAC/aqueous solution of $\mathrm{ZnBr}_{2}$, were synthesized. The first step of the process was carried out at $100^{\circ} \mathrm{C}$ (or 
at $70^{\circ} \mathrm{C}$ for allyl chloride as a substrate) for $1 \mathrm{~h}$, and the second stage at a temperature of $100{ }^{\circ} \mathrm{C}$ and a pressure of $0.9 \mathrm{MPa} \mathrm{CO}$ for $4 \mathrm{~h}$.

Cyclic carbonates were obtained in yields within a range of $50-77 \%$ (Table 3). Only in the case of cyclohexene as a substrate, despite the high conversion of $\mathrm{CO}_{2}$, carbonate yield was low (4\%). It is most probably due to the fact that in situ generated 1,2-epoxy cyclohexane can undergo polymerization and copolymerization reaction with carbon dioxide [15]. It is necessary to emphasize that in many studies in the literature concerning the direct synthesis of cyclic carbonates from olefins and $\mathrm{CO}_{2}$, only the possibility of obtaining of styrene carbonate was examined.

\section{Conclusions}

An effective one-pot method for the direct synthesis of cyclic carbonates from $\mathrm{CO}_{2}$ and olefins in the presence of tert-butyl hydroperoxide as an oxidant using the system consisting of $\mathrm{MoO}_{2}(\mathrm{acac})_{2}$ and PS-TBMAC/aqueous solution of $\mathrm{ZnBr}_{2}$, was developed. Compared with the method described in the literature using $\mathrm{MoO}_{2}(\mathrm{acac})_{2}$ - $\mathrm{TBAB}$ as a catalytic system (the first step: $100^{\circ} \mathrm{C}, 1 \mathrm{~h}$, the second step: $140^{\circ} \mathrm{C}, \mathrm{CO}_{2}$ pressure of $3 \mathrm{MPa}, 1 \mathrm{~h}$ ), our proposed method allows to achieve similar yields of cyclic carbonates under milder reaction conditions $\left(100^{\circ} \mathrm{C}, \mathrm{CO}_{2}\right.$ pressure of $0.9 \mathrm{MPa}$ ) and enables easy separation of PS-TBMAC and its use several times without loss in its activity. The use of immobilized quaternary ammonium salt rather than its soluble counterpart, not only simplified the procedure for its removal from the reaction mixture, but also positively influenced the catalyst stability.

Open Access This article is distributed under the terms of the Creative Commons Attribution 4.0 International License (http:// creativecommons.org/licenses/by/4.0/), which permits unrestricted use, distribution, and reproduction in any medium, provided you give appropriate credit to the original author(s) and the source, provide a link to the Creative Commons license, and indicate if changes were made.

\section{References}

1. Shaikh AAG, Sivaram (1996) Chem Rev 96:951

2. Schäffner B, Schäffner F, Verevkin SP, Börner A (2010) Chem Rev 110:4554

3. Xu K (2004) Chem Rev 104:4303

4. Clements JH (2003) Ind Eng Chem Res 42:663

5. North M, Pasquale R, Young C (2010) Green Chem 12:1514.

6. Verdol JA (1962) US Patent 3205305.

7. Sun J, Lin Liang L, Sun J, Jiang Y, Lin K, Xu X, Wang R Catal Surv Asia (2011) 1549

8. Dibenedetto A (2014) Angelini, ch. 2. In: Aresta M, Eldik R (eds) Advances in inorganic chemistry, vol 66. Elsevier, Waltham

9. Srivastava R, Srinivas D, Ratnasamy P (2003) Catal Lett 91:133

10. Sun J, Fujita S, Bhanage BM, Arai M (2004) Catal Commun $5: 83$

11. Sun J, Fujita S, Bhanage BM, Arai M (2004) Catal Today 93:383.

12. Sun J, Fujita S, Zhao F, Hasegawa M, Arai M (2005) J Catal 230:398.

13. Wang Y, Sun J, Xiang D, Wang L, Sun J, Xiao F (2009) Catal Lett 129:437

14. Xiang D, Liu X, Sun J, Xiao F (2009) Sun J Catal Today 148:383

15. Chen F, Dong T, Xu T, Xiaofang Li X, Hu C (2011) Green Chem 13:2518.

16. Olga V, Zalomaeva OV, Nataliya V, Maksimchuk NV, Chibiryaev AM, Kovalenko KA, Fedin VP, Balzhinimaev BS (2013) J Energy Chem 22:130

17. Girard AL, Simon N, Zanatta M, Marmitt S, Gonçalves P, Dupont J (2014) Green Chem 16:2815.

18. Han Q, Qi B, Ren W, He C, Niu J, Duan C (2015) Nat Commun $6: 1$

19. Ramidi P, Felton CM, Subedi BP, Zhou H, Tian ZR, Gartia Y, Pierce BS, Ghosh A (2015) J CO2 Util 9:48.

20. Maksimchuk NV, Ivanchikova I D, Ayupov AB, Kholdeeva OA (2016) Appl Catal B 181:363.

21. Siewniak A, Jasiak K, Baj S (2014) Appl Catal A 482:266.

22. Jasiak K, Krawczyk T, Pawlyta M, Jakóbik-Kolon A, Baj S (2016) Catal Lett 146:893

23. Paul S, Zhu Y, Romain C, Brooks R, Saini PK, Williams CK (2016) Chem Commun 51:6459 